\title{
Evolución de la mortalidad materna en Argentina y Paraguay entre 1990 y 2015; políticas públicas, desigualdades y desafíos
}

\author{
Evolution of Maternal Mortality in Argentina and \\ Paraguay Between 1990 and 2015; Public Policies, \\ Inequalities and Challenges
}

María Alejandra Fantin ${ }^{1}$

Instituto de Investigaciones Geohistóricas (IIGHI), Universidad Nacional del Nordeste (UNNE), Resistencia, Argentina. Consejo Nacional de Investigaciones Científicas y Técnicas (CONICET), Resistencia, Argentina.

mafantin@gmail.com

http://orcid.org/0000-0001-6432-3843

\section{Claudina Zavattiero ${ }^{2}$}

Instituto de Investigaciones Geohistóricas (IIGHI), Universidad Nacional del Nordeste (UNNE), Resistencia, Argentina. Consejo Nacional de Investigaciones Científicas y Técnicas (CONICET), Resistencia, Argentina. claudinaz@hotmail.com http://orcid.org/0000-0002-1767-7822 


\section{Resumen}

El artículo tiene como objetivo analizar y comparar la evolución y situación actual de la mortalidad materna en Argentina y Paraguay, revisar las medidas de políticas públicas que cada país ha implementado y plantear los desafíos para lograr la reducción de las muertes maternas. Se aplican técnicas descriptivas y análisis comparativo a partir de los datos de anuarios estadísticos publicados por los Ministerios de Salud de ambos países. El estudio concluye que la muerte de una mujer por causas relacionadas al embarazo, parto o puerperio es un problema grave en Paraguay, cuya magnitud duplica los valores registrados en Argentina. En la zona de frontera de ambos países, los niveles de mortalidad adquieren valores similares evidenciando una inequitativa distribución de las muertes maternas sobre la superficie. Paraguay, a pesar de tener un mayor despliegue legal y programático que Argentina, debe considerar además de las causas directas, los obstáculos sociales y económicos.

Palabras clave: mortalidad; desigualdad; desafíos; Argentina; Paraguay.

\section{Abstract}

The objective of this paper is to analyze and compare the evolution and current situation of maternal mortality in Argentina and Paraguay, review the measures of public policies that each country has taken and pose the challenges to achieve for the reduction of maternal deaths. Descriptive techniques and comparative analysis are applied based on data from statistical yearbooks published by the Ministries of Health of both countries. The study concludes that the death of a woman due to causes related to pregnancy, childbirth or puerperium is a serious problem in Paraguay, whose magnitude doubles the values registered in Argentina. In the border area of both countries, mortality levels acquire similar values evidencing an inequitable distribution of maternal deaths on the surface. Paraguay, despite having a greater legal and programmatic deployment than Argentina, should consider, in addition to the direct causes, the social and economic obstacles.

Key words: Mortality; Inequalities; Challenges; Argentina; Paraguay.

¿Cómo citar este artículo? / How to quote this article?

Fantin, M. A. y Zavattiero, C. (2019). Evolución de la mortalidad materna en Argentina y Paraguay entre 1990 y 2015; políticas públicas, desigualdades y desafíos. Sociedad y economía, (38), 21-44. https://doi.org/10.25100/sye.voi38.8024 


\section{Introducción}

Una muerte materna es el resultado de una serie de acontecimientos que revelan el incumplimiento de ciertos derechos como los sexuales y reproductivos ${ }^{3}$, la equidad de género y el empoderamiento de las mujeres ${ }^{4}$ (MSPBS, 2005; Burgos, 2015; Karolinski et al., 2015; Elu y Santos, 2004). Según Cook (citada en Acosta, 1999) la mortalidad materna atenta contra el derecho a la vida, la libertad y la seguridad personal, el derecho a la información y la educación en salud, que comprende la información sobre la salud reproductiva. Incluida la planificación familiar (Arteaga y López, 2009), el derecho al cuidado de la salud y a beneficiarse del progreso científico, y los derechos relacionados con la igualdad y la no discriminación.

La prevención de las defunciones maternas se ha convertido, desde hace décadas, en una prioridad internacional, puesto que repercuten negativamente en la esperanza de vida de las mujeres (Brizuela, 2005), en el entorno familiar y social, tienen implicaciones económicas y en políticas públicas (Rodríguez y Verdú, 2013) e inciden en el desarrollo de los países (Arteaga y López, 2009; Burgos, 2015). A este escenario también se añade el probable agravante de arrastrar consigo la vida de un hijo nacido en malas condiciones.

Una de las metas de los Objetivos de Desarrollo Sostenible, último acuerdo mundial (2015), es reducir la razón de mortalidad materna mundial a menos de 70 por 100 mil nacidos vivos entre 2016 y 2030, y lograr que ningún país tenga una mortalidad materna que supere el doble de la media mundial. Las mencionadas metas se dan en el marco de una serie de iniciativas, propuestas y compromisos

3 El derecho a la salud, incluida la salud sexual y reproductiva, ha sido reconocido por varios órganos de derechos humanos, como el Comité de Derechos Económicos, Sociales y Culturales en su observación general $n^{\circ}$ 22 (2016) y el Comité para la Eliminación de la discriminación contra la Mujer en su observación general nº 24 (1999) (UNFPA, UNICEF, ONU Mujeres, 2018).

4 Permite a las mujeres elegir sus propias alternativas y proporcionarles información adecuada para tomar decisiones cruciales en lo referente a su salud y, por consiguiente, ejercer sus derechos (MSPBS, 2005). internacionales previos en el ámbito de la salud, de la mujer, y de la población y el desarrollo5. En América Latina y el Caribe se cuenta con el "Plan de acción para acelerar la reducción de la mortalidad materna y la morbilidad materna grave" aprobado por los Ministros de Salud de las Américas, en la $51^{\circ}$ Reunión del Consejo Directivo de 20ll, mediante la Resolución CD51.R12, y cuyo objetivo es contribuir a acelerar la reducción de la mortalidad materna.

La mortalidad materna adquiere la connotación de problemática social en la medida en que su ocurrencia está ampliamente relacionada con grupos socialmente postergados, carentes de oportunidades, y en situación de pobreza y desigualdad (BM, 2006; Karolinski et al., 2015). La mortalidad materna es mayor en las zonas rurales, urbano-marginales, en las comunidades más pobres (GTR, 2012; OMS, 2018), entre mujeres indígenas (UNFPA, UNICEF, ONU Mujeres, 2018), de menor educación o analfabetas (Arteaga y López, 2009), con mayor número de hijos, y entre quienes viven lejos de los servicios de salud (Mancuello, 2015).

\section{Según Gómez (1997):}

\begin{abstract}
Las raíces de este problema se encuentran no sólo en las condiciones de pobreza relacionadas con bajos niveles de desarrollo económico, sino también en la posición social de subordinación que ocupa la mujer en las distintas sociedades; esta posición genera o exacerba factores de riesgo biológico vinculados a la maternidad, e incide en las prioridades nacionales, locales y familiares que guían la inversión de recursos para responder a esos riesgos (p. 28).
\end{abstract}

5 La Declaración de Alma-Ata de la Conferencia Internacional sobre Atención Primaria de Salud, en 1978, la Convención sobre la Eliminación de todas las Formas de Discriminación contra la Mujer en 1979, la Conferencia Internacional sobre la Maternidad sin Riesgos en 1987, la Conferencia Sanitaria Panamericana en 1990, la Conferencia Internacional sobre la Población y el Desarrollo en 1994, la Cumbre Mundial sobre Desarrollo Social en 1995 y la Cuarta Conferencia Mundial sobre la Mujer, en 1995. Asimismo, cabe resaltar la importancia que le han dado a este tema las Conferencias Internacionales de la Mujer y la Conferencia Regional sobre Población y Desarrollo de América Latina y el Caribe, durante la cual se aprobó el Consenso de Montevideo sobre Población y Desarrollo, en 2013. 
Estimaciones recientes de la Organización Mundial de la Salud (OMS) dan cuenta de que en 2015 unas 303 mil mujeres en el mundo perdieron la vida por causas relacionadas con la maternidad. De esas defunciones, el $99 \%$ correspondió a países en vías de desarrollo 6 , la mayoría de ellas vive en situación de pobreza y tiene acceso limitado a atención obstétrica de calidad (OMS, 2015; GTR, 2012). Además debe contemplarse que en los casos en los que se evita la muerte, un número de mujeres queda con secuelas derivadas de la morbilidad materna. Así, por cada muerte materna acaecida, la OMS estima que entre 30 y 100 mujeres quedan, en menor o mayor grado, discapacitadas (Elu y Santos, 2004).

En América Latina, alrededor de 6,6 mil mujeres murieron por causas maternas en 2015. Lo que representa 60 muertes por cada 100 mil nacidos vivos, fluctuando entre 15 defunciones en Uruguay y 206 defunciones en Bolivia (OMS, 2015).

Numerosos estudios, a nivel internacional y en latinoamericana, han demostrado que la mayor parte de las muertes maternas son evitables y que desde hace muchos años se cuenta con el conocimiento científico y la tecnología requerida para impedirlas (Padilla y McNaughton, 2003; Gómez, 1997; UNICEF, 2009). El acceso a servicios básicos de salud y nutrición antes, durante y después del parto ${ }^{7}$, a métodos de planificación familiar ${ }^{8}$, a la atención prenatal temprana, al parto institucional con atención médica cualificada, al manejo adecuado de complicaciones obstétricas y al control post parto temprano -todos ellos culturalmente accesibles- constituye un

6 Esto no implica que las mujeres de países desarrollados no presenten complicaciones obstétricas durante el embarazo, el parto o después de él, sino que es más probable que ellas accedan oportunamente a tratamiento efectivo y no mueran (Burgos, 2015).

7 Las iniciativas de programas, como los suplementos nutricionales y la promoción de la nutrición apropiada, ayudan a disminuir las complicaciones por carencias nutricionales (Arteaga y López, 2009).

8 El acceso de todas las mujeres a la planificación familiar, y el tratamiento oportuno y de calidad de las complicaciones del aborto (espontáneo o inducido), reduce el número de defunciones maternas (MSPBS, 2005). componente central en la prevención de dichas muertes (BM, 2006). Todo ello conforma un nuevo paradigma en la atención maternal y neonatal, a partir de estrategias de una maternidad segura (Uribe, 2009).

Dentro de este marco, el presente artículo tiene la finalidad de analizar y comparar la evolución y situación actual de la mortalidad materna en Argentina y Paraguay (principalmente entre 2010 y 2015). Mostrando las desigualdades entre los países estudiados y al interior de cada uno; así como las políticas públicas emprendidas por ambos para tratar de disminuir la gravedad de la problemática analizada y los desafíos a futuro.

La elección de dichos países obedece a que, si bien son limítrofes y en sus fronteras comparten ciertas características poblacionales y sanitarias (Fantin, 2008), presentan heterogeneidad social, económica, territorial, cultural y variaciones sustanciales en su capacidad de dar respuesta a las necesidades y demandas de la población, por lo que se considera que los avances de un país pueden servir de experiencia al otro.

Para cumplir con el objetivo, se aplican técnicas descriptivas a partir de datos transversales y retrospectivos, además de revisión documental. El análisis comparativo se lleva a cabo a partir de los datos disponibles en los anuarios publicados por la Dirección de Estadísticas e Información de Salud, del Ministerio de Salud de la Argentina (MS) y en los Anuarios de Indicadores de Mortalidad publicados por la Dirección de Estadísticas en Salud, del Ministerio de Salud Pública y Bienestar Social del Paraguay (MSPBS). Ambos basados en los registros de estadísticas vitales. La descripción de las políticas públicas, normativas e institucionalidad se realiza a partir de una recopilación y revisión de políticas, programas y estrategias adoptadas por los países, e información recabada de los Ministerios de Salud.

Se asume la definición otorgada por la décima revisión de la Clasificación Internacional de Enfermedades (CIE-10) que considera a la muerte materna como la defunción de una mujer 
(mientras está embarazada o dentro de los cuarenta y dos días siguientes a la terminación del embarazo, independientemente de la duración y el sitio de la gestación) debida a cualquier causa relacionada con -o agravada por- el embarazo mismo o su atención, pero no por causas accidentales o incidentales (OMS, 1992).

Para el análisis de las principales causas de mortalidad materna se utiliza la codificación de la CIE-10. Las defunciones maternas pueden subdividirse en dos grupos: las defunciones obstétricas directas, que resultan de complicaciones obstétricas del embarazo, parto y puerperio, de intervenciones, de omisiones, de tratamiento incorrecto, o de una cadena de acontecimientos originada en cualquiera de las circunstancias mencionadas. En tanto, las causas obstétricas indirectas son las que resultan de una enfermedad existente desde antes del embarazo o de una enfermedad que evoluciona durante el mismo, no debidas a causas obstétricas directas, pero sí agravadas por los efectos fisiológicos del embarazo: en estas se incluyen anemia, paludismo, enfermedades coronarias y VIH (OPS, 1995).

El indicador más utilizado en este documento es la Razón de Mortalidad Materna (RMM), que consiste en el cociente entre el número de muertes maternas (asociadas al embarazo, parto o post parto) durante un período de tiempo dado y el número de nacidos vivos en el mismo periodo (cada 100 mil nacidos vivos). El mismo, indica el riesgo de muerte materna relativo a los nacimientos (GTR, 2012)9. Para analizar la evolución de la RMM y sus causas, se calculan promedios trianuales para suavizar posibles situaciones coyunturales de la mortalidad y errores en el registro de los hechos vitales.

Cabe advertir que la falta de datos precisos representa una de las principales dificultades al

9 Se utiliza como denominador el número de nacidos vivos como una aproximación al número de mujeres expuestas a morir por causas relacionadas con el embarazo, el parto y el puerperio. Este indicador no mide el riesgo obstétrico, puesto que no incluye en el denominador los embarazos que no terminaron en nacimientos vivos, pero que pueden ser responsables de una muerte materna. abordar las defunciones maternas. Las múltiples causales que pueden intervenir en este tipo de defunción suelen ocasionar un inadecuado registro que se traduce en una clasificación errónea y consecuente subregistro de la muerte materna en los sistemas nacionales de estadísticas vitales. A lo anterior, se adiciona el hecho que los registros civiles suelen ser incompletos o carecen de cobertura total, por lo que una parte de las muertes de mujeres en edad fértil no es registrada, así como tampoco algunos nacimientos (GTR, 2012) ${ }^{10}$.

Para atenuar dicha situación, en 2001, Argentina incorporó una pregunta a los formularios estadísticos de defunción que le permite identificar más adecuadamente los casos de muertes maternas y, en consecuencia, conocer con mayor precisión el nivel de la tasa de mortalidad materna (MS, 2015a). En Paraguay, también existe un creciente interés por documentar y mejorar la detección de los casos de muertes maternas, que llevó a la realización de estudios regionales entre los años 2007 y 2011. Desde 2011 se realizan procedimientos para la detección de las muertes maternas, así como la reactivación de la Comisión Técnica Nacional de Salud y Morbimortalidad Materna, en 2013 (Ruiz et al., 2015).

El artículo está estructurado en cuatro partes. La primera, muestra los principales hitos en la construcción de políticas públicas destinadas a la reducción de la mortalidad materna. El segundo apartado describe el contexto demográfico y la situación de la salud materna en cada país. La tercera parte aborda la evolución y el nivel de la mortalidad materna; y la cuarta, las principales

10 Estudios cuidadosos, realizados en Francia y en Estados Unidos, muestran que una proporción importante -frecuentemente hasta un tercio- de muertes, que deben ser registradas como maternas, están clasificadas erróneamente (Bouvier-Colle et cols., 1991 y Berg et cols., 1996, citados en Hill et al., 2001). En el Paraguay, el subregistro de nacimientos asciende al 19,6\% y el de defunciones, al 25,2\% (MSPBS/DIGIES/DES, 2015). La Argentina tiene sistemas de registro de defunciones con cobertura total. Sin embargo, es preciso alertar acerca de la posibilidad de mayores niveles de subregistro en zonas alejadas y con difícil acceso a la red de servicios, aspecto que impide captar fehacientemente la realidad presentada. 
causas de muerte materna. En las dos últimas, se revelan las desigualdades entre países así como al interior de cada país.

\section{Hitos en la construcción de políticas públicas para la reducción de la mortalidad materna}

Según el MS y UNICEF (2003) el problema de la mortalidad materna "puede y debe disminuir, en la medida en que se definan y desarrollen políticas coherentes y acciones sostenidas en el tiempo" (p. 5). En este sentido, a continuación se presentan los principales hitos que dieron lugar a la construcción de políticas públicas tendientes a reducir la mortalidad materna, en los países analizados.

En la Argentina, a mediados de la década de los años ochenta, se comienza a incluir el tema de salud sexual y reproductiva en la agenda tanto pública como política:

\begin{abstract}
Hasta esa fecha, el silencio de las autoridades sobre la salud reproductiva y los derechos sexuales y reproductivos de la población, en particular de las mujeres, se debió básicamente a dos motivos. Por un lado, a las restricciones normativas con relación a la planificación familiar vigentes en la Argentina desde mediados de la década de 1970 hasta mediados de los $1980^{11} \mathrm{y}$, por otro, a la ausencia de un debate en la sociedad que ubicara en el centro de la agenda pública los intereses y derechos de las mujeres respecto de la sexualidad y la reproducción (MS y UNICEF, 2003, p. 195).
\end{abstract}

La situación se modificó en torno a los noventa con la primera experiencia de política pública: "Programa de Procreación Responsable" (1988). Del mismo modo, la Reforma Constitucional de 1994 significó un importante avance, en el reconocimiento de los derechos de las mujeres, al

11 Decreto No 659/1974 y Decreto No $3.938 / 1977$ restrictivos en materia de anticoncepción emitidos por el gobierno militar, derogados por Decreto $\mathrm{N}^{\circ} 2.274 / 1986$. incorporar, con rango constitucional, el tratado firmado en la Convención sobre la Eliminación de todas las Formas de Discriminación contra la Mujer.

En esa misma década, diversas provincias y municipios dictaron leyes de salud reproductiva que reconocen los derechos de mujeres y varones a regular su fecundidad e impulsan programas de salud reproductiva. Estos, en general, tienen como objetivo brindar información sobre las diversas técnicas de control de la natalidad, sobre la necesidad de la utilización de preservativos para evitar el contagio de HIV y establecer claramente que los médicos podrán ordenar estas prácticas (MS y UNICEF, 2003).

En el ámbito nacional, en el año 2002, se sancionó la Ley $\mathrm{N}^{\circ} \mathbf{2 5} .673$ de salud sexual y procreación responsable, que reglamenta la creación del Programa Nacional de Salud Sexual y Procreación Responsable (2003) bajo jurisdicción del Ministerio de Salud ${ }^{12}$. De esta manera, por primera vez en el país, se incorporó la salud sexual y reproductiva a la agenda de las políticas públicas del Estado nacional y se estableció explícitamente el objetivo de disminuir la morbimortalidad materna en el Art. 2 de la Ley $\mathrm{N}^{\circ}$ 25.673/2002 (Congreso de la Nación Argentina, 2002b).

El marco expuesto sirvió para crear institucionalidad al interior del Ministerio de Salud ${ }^{13} \mathrm{y}$ dar lugar a planes como el "Plan Estratégico para la Reducción de la Mortalidad Materna y la Mortalidad Infantil 2009-2011" y el "Plan Operativo para la Reducción de la Mortalidad Materna-infantil, de las madres y de las adolescentes" (2009, formalizado a través de la Resolución $\mathrm{N}^{\circ}$

12 La ley se inscribe en el marco de diversos tratados internacionales: Declaración Universal de los Derechos Humanos, Convención Internacional de los Derechos del Niño, Pacto Internacional de Derechos Económicos, Sociales y Culturales, Convención sobre la eliminación de todas las formas de Discriminación contra la mujer, Acuerdos de El Cairo (1994), Beijing (1995) y Objetivos de Desarrollo del Milenio.

13 Dirección Nacional de Maternidad e Infancia, Programas de Salud Integral de la Adolescencia, Salud Sexual y Procreación Responsable, y los Comités de Análisis de las Mortalidades Materna e Infantil, entre otros. 
1087/2010) a cargo de la Subsecretaría de Medicina Comunitaria, Maternidad e Infancia, del Ministerio de Salud de la Nación.

El Plan se centra en detectar las principales causales que desencadenan la muerte de mujeres, adolescentes, niños y niñas para actuar sobre ellas, y trata de hacer énfasis en los procesos de gestión, recursos humanos, insumos e infraestructura que signifiquen un obstáculo para la correcta atención de la población en cada provincia (MS, 2009). Está compuesto a su vez por el Plan Nacer (2004) ${ }^{14}$ y ampliado al Programa SUMAR (2012) ${ }^{15}$ (Burgos, 2015). Su implementación tuvo lugar en las provincias que fueron suscribiendo, paulatinamente, acuerdos políticos en los máximos niveles de conducción (MS, s.f.).

Para abordar la Atención Obstétrica de Emergencia básica e integral, Argentina desarrolló como estrategia la Regionalización Perinatal (organización de la atención materno feto neonatal con distintos niveles de complejidad). El Programa, tanto en su expresión nacional como provincial, aborda la atención del aborto a través de la elaboración de la Guía de Atención en casos de Aborto no Punible (2010), y protocolos para víctimas de la violencia sexual. El Programa de Mejoramiento de la Calidad de Atención Post Aborto cuenta con una guía de atención post aborto y tiene como principal propósito brindar un trato humanizado a las pacientes que consulten por complicaciones de abortos y la asistencia para la anticoncepción.

14 Es un programa federal del Ministerio de Salud de la Nación que busca mejorar la cobertura de salud y la calidad de atención de las mujeres embarazadas, embarazadas adolescentes, puérperas y de los niños/as menores de 6 años. Establece una serie de prestaciones de controles prenatales e incluye una asignación por embarazo para protección social, ingreso reconocido por el Estado para aquellas mujeres embarazadas residentes en la República Argentina que se encuentran en situación de vulnerabilidad. Establece medidas específicas para poblaciones vulnerables como adolescentes escolarizadas y mujeres privadas de la libertad (Burgos, 2015).

15 Es la ampliación iniciada en 2007 del Plan Nacer, que además de brindar cobertura a la población materno infantil, incorpora a los niños/as y adolescentes de 6 a 19 años, y a las mujeres hasta los 64 años (Burgos, 2015).
Además, se debe destacar que el país posee una ley específica de educación sexual (Ley $\mathrm{N}^{\circ}$ 26.150/2006, Congreso de la Nación Argentina, 2006) que establece el derecho de todos los educandos a recibir educación sexual integral y crea el Programa Nacional de Educación Sexual Integral (ESI), a cargo del Ministerio de Educación. Por su parte, la Ley No $25.584 / 2002$ (Congreso de la Nación Argentina, 2002a), de embarazo y maternidad adolescente, prohíbe, en establecimientos de educación pública, las acciones que impidan el inicio o continuidad del ciclo escolar a alumnas embarazadas o madres en período de lactancia.

En Paraguay, las acciones más relevantes en salud materna, y por ende tendientes a reducir las muertes maternas, se han realizado a partir de la caída de la dictadura militar (1989). Desde entonces, se registran promulgaciones legales que incluyen el tema en diversos niveles legislativos como su incorporación en la Constitución de 1992, en Códigos como el Civil (Ley No 1/92 de Reforma parcial del Código Civil, Congreso de la Nación Paraguaya, 1992), el Laboral (Ley No 213/93, Congreso de la Nación Paraguaya, 1993), el Penal (Ley $\mathrm{N}^{\circ} 1.160 / 97$, Congreso de la Nación Paraguaya, 1997) y el de la Niñez y la Adolescencia (Ley $\mathrm{N}^{\circ}$ 1.680/2001, Congreso de la Nación Paraguaya, 2001), además de legislaciones especificas del MSPBS.

La Constitución de 1992 incluye artículos del derecho a la vida (Art. 4), de la maternidad y la paternidad (Art. 55), de la planificación familiar y de la salud materna-infantil (Art. 61) y del derecho a la salud (Art. 68). En la Ley de Reforma del Código Civil se reproducen las ideas contenidas en los artículos constitucionales (en su artículo 13 ratifica lo enunciado en el artículo 61 de la Constitución). Por su parte, el Código Laboral al hacer referencia al trabajo de las mujeres, establece varios artículos sobre los derechos y obligaciones laborales durante la maternidad (Art. 130 a 135). El Código Penal vigente tipifica los homicidios en distintos grados, con artículos que se refieren a la penalización en relación a los abortos (109, 349 a 353). Las disposiciones referidas a la maternidad también están contem- 
pladas en el Código de la Niñez y la Adolescencia en los siguientes artículos: $9^{\circ}, 10^{\circ}, 11^{\circ}, 12^{\circ}, 13^{\circ}, 14^{\circ}$, $204^{\circ}, 205^{\circ}, 206^{\circ}, 207^{\circ}$ y $208^{\circ}$.

A nivel de gobierno, se vienen realizando esfuerzos para la atención de la mujer embarazada, el parto y el puerperio. En 2006, el Congreso de Paraguay sancionó la Ley No 2.907 denominada “De aseguramiento presupuestario de los programas de salud reproductiva y de aprovisionamiento del kit de partos" (Congreso de la Nación Paraguaya, 2006), que destina fondos para adquirir productos básicos para la salud reproductiva, incluidos los anticonceptivos ${ }^{16}$. En 2008, las Políticas Públicas para la Calidad de Vida y Salud con Equidad tenían como meta la indiferencia cero para situaciones como los sufrimientos innecesarios y las muertes evitables para las mujeres, garantizando la atención gratuita en todos los servicios de salud pública del país, incluyendo la entrega de medicamentos básicos durante el embarazo y el parto (normal o cesárea) ${ }^{17}$. Otras importantes leyes se dieron en 2010 y 2015: la Ley $\mathrm{N}^{\circ}$ 4.084/2010 (Congreso de la Nación Paraguaya, 2010) de protección a las estudiantes en estado de gravidez y maternidad y la Ley $\mathrm{N}^{\circ} 5.508 / 2015$ (Congreso de la Nación Paraguaya, 2015) de protección de la maternidad y apoyo a la lactancia.

Respecto a planes específicos, el país cuenta con la tercera versión del Plan Nacional de Salud Sexual y Reproductiva vigente en el periodo 20142018, el cual ha definido como una de las priori-

16 Desde 2010, el Gobierno de la República del Paraguay tomó la plena responsabilidad financiera para la compra de anticonceptivos.

17 Si bien desde hace varios años se venían implementando diferentes medidas de exoneración del cobro de aranceles a diversos segmentos de la población (en 2000, en menores de 5 años y embarazadas; en 2006, se extiende a menores de 10 años y, para el 2007, se amplía la atención gratuita a embarazadas y recién nacidos, posteriormente se extiende la gratuidad hasta la adolescencia y población vulnerable, incluyendo la entrega de medicamentos básicos esenciales y vacunas), no fue hasta finales del 2009 que se logra la exoneración de pago de aranceles para todas las prestaciones médicas y odontológicas, medicamentos, insumos biológicos y servicios de ambulancia ofrecidos en todos los hospitales, centros y puestos de salud, unidades de salud de la familia y otras dependencias de la red de servicios del MSPBS. dades del área estratégica de maternidad segura, la disminución de la mortalidad materna. Le anteceden a esta versión las "Normas de Atención Humanizada Post Aborto", de 2012, en las cuales se plasma cómo manejar adecuadamente esta patología frecuente que puede llevar a la muerte (Mancuello, 2015). El MSPBS ha aprobado, en 2012, la Resolución Ministerial No 146 sobre la atención humanizada a las pacientes en situación de aborto.

El MSPBS cuenta con un sistema de Vigilancia Epidemiológica de la Salud, Morbilidad y Mortalidad Materna y Neonatal (VESMMN), una Comisión Técnica Nacional de Salud y Morbimortalidad Materna reactivada desde 2013 y una Dirección General de Vigilancia de Salud. Como parte de la estrategia para la reducción de la mortalidad materna, se estableció el carácter obligatorio de la notificación de la defunción materna en los servicios de salud (Ruiz et al., 2015). La estrategia de la Red Integrada de Servicios de Salud articulada con las Unidades de Salud de la Familia permite la derivación de una atención obstétrica de emergencia (AOE). No obstante, la distribución de las instalaciones de AOE en el territorio no es adecuada (Burgos, 2015).

Actualmente dispone de una iniciativa nacional denominada "Movilización Nacional para la disminución de la mortalidad materna y del recién nacido 2014-2018", con la finalidad de reducir, en un $20 \%$, estas muertes. Le antecede el "Plan de acción para la disminución acelerada de la mortalidad materna y de la morbilidad materna severa 2012-2017" (MSPBS, 2012).

Finalmente, cabe señalar que la Ley $N^{\circ} 1264 / 1998$ General de Educación (Congreso de la Nación Paraguaya, 1998) brinda el marco de derechos y equidad en el que se inserta la educación integral de la sexualidad y se concreta en el Plan Nacional de Educación 2024. Sin embargo, el Ministerio de Educación resolvió no poner en vigencia el Marco Rector Pedagógico debido a la fuerte oposición de grupos fundamentalistas, habiéndose incorporado la educación en sexualidad en la malla curricular de los bachilleratos técnicos en salud, desde el año 2013 (Binstock, 2016). 


\section{Contexto demográfico y de la salud materna}

Este apartado presenta las características demográficas y de la salud materna más relevantes de los países analizados, teniendo en cuenta que el contexto, expresado a través de sus múltiples facetas (políticas, socioeconómicas, culturales, territoriales e institucionales), es un potente determinante que explica la variación de los indicadores de salud y, en especial, el análisis del contexto de la salud materna constituye una pieza fundamental en la caracterización del problema de la mortalidad materna (Karolinski et al., 2015).

- El comportamiento de las tasas de fecundidad y mortalidad revela que Argentina se encuentra en un estadio de transición demográfica avanzada y Paraguay en plena transición ${ }^{18}$, lo que se traduce en estructuras por edades de la población notablemente diferentes:

- La población de Argentina, al 2015, está conformada por aproximadamente 43,3 millones de habitantes que residen, en su mayoría, en zonas urbanas $(91,8 \%)$. Con una tasa de crecimiento media anual del orden de 8,9 personas por mil habitantes cada año, presenta una estructura de población envejecida: el grupo menor a 30 años de edad representa el $48,6 \%$ de la población, en tanto, la población de 60 años y más asciende a 15,2\% (CELADE y CEPAL, 2017).

- La población de Paraguay, de más de 6,6 millones de habitantes en 2015, crece a un ritmo más acelerado que su vecino país $(14,3$

18 Se consideran países en transición incipiente aquellos que exhiben alta natalidad y mortalidad. En la etapa de transición moderada, se encuentran los países de alta natalidad, pero cuya mortalidad ya puede calificarse de moderada, con un crecimiento natural todavía elevado, cercano al 3\%. En plena transición están los países con natalidad moderada y mortalidad moderada o baja, lo que determina un crecimiento natural moderado, cercano al $2 \%$ (entre $1,7 \%$ y 2,5\%). En la etapa de transición avanzada se ubican los países con natalidad y mortalidad moderada o baja, lo que se traduce en un crecimiento natural bajo, del orden del $1 \%$ (entre $0,5 \%$ y $1,5 \%$ ) (CELADE, 2005). por mil habitantes anualmente), tiene una parte importante de su población en zonas rurales $(33,6 \%)^{19}$ y se caracteriza por presentar una estructura de población con incipiente envejecimiento $59,4 \%$ de la población tiene menos de 30 años y $9 \%$ tiene 60 años y más) (CELADE y CEPAL, 2017).

En Argentina, existe un predominio de población femenina, con una tasa de masculinidad de 96,6 varones por cada 100 mujeres, mientras en Paraguay la relación es inversa: con mayoría de población masculina (relación de 103 varones por cada 100 mujeres). El grupo de mujeres en edad fértil (15 a 49 años) está compuesto por el $48,7 \%$ del total de mujeres en Argentina y por el $53 \%$ en Paraguay, en este último caso, producto de las tasas más elevadas de fecundidad del pasado. Lo mencionado, en combinación con la estructura por edades de población, da lugar a un mayor peso de población femenina adolescente (10 a 19 años) entre las mujeres en edad fértil en Paraguay frente a Argentina (20,1\% y $15,5 \%$, respectivamente) y tasas de natalidad que, si bien en el caso de Paraguay presentan valores moderados en el periodo 2015-2020 (20 por mil habitantes), son más elevadas que en países con mayor envejecimiento como Argentina (16,5 por mil habitantes) (CELADE y CEPAL, 2017).

Por otra parte, la tasa de mortalidad infantil en Paraguay es superior a la registrada en Argentina en 2015 (14,2 y 9,7 por mil nacidos vivos respectivamente, según los anuarios de los ministerios). Por ende, la esperanza de vida al nacer en Paraguay es más baja que en Argentina ( 73,7 y 76,8 respectivamente, en el periodo 2015-2020) (CELADE y CEPAL, 2017).

En este ámbito, es importante señalar que las causas por las cuales puede morir una persona son muy variadas, y en el caso de las mujeres se agrega la muerte por causa del embarazo, parto y puerperio. En 2015, dichas muertes representan el $2 \%$ del total de muertes de las mujeres en

19 El grado de urbanización se asocia habitualmente en sentido inverso con el nivel de la fecundidad y el de mortalidad materna (Rajs, Parada y Peyser, 1994). 
edad fértil (10 a 49 años) en Argentina y el 6,4\% en Paraguay. En valores absolutos, en Argentina, se registran 298 defunciones y, en Paraguay, 98 muertes, según los anuarios de ambos países.

La disparidad relativa puede obedecer a factores demográficos como los presentados brevemente arriba, ya que según Hill et al. "menos nacimientos producen menos muertes maternas, aunque no existan nuevas intervenciones de salud de la mujer"20 (2001 p. 14), pero también a aspectos relacionados con las condiciones de salud sexual y reproductiva en cada uno de los países, como se comenta a continuación.

Según el informe sobre estado de la población mundial (UNFPA, 2017), el uso de anticonceptivos modernos por parte de las mujeres en edad fértil (15 a 49 años de edad) es levemente superior en Argentina que en Paraguay (70\% y $67 \%$ respectivamente), así como el porcentaje de mujeres en edad fértil con demanda satisfecha de anticonceptivos modernos (85\% y $81 \%$ respectivamente). Cabe destacar que la prevalencia de uso de métodos anticonceptivos modernos es la principal razón de disminución de la tasa global de fecundidad (CEPEP, 2009) e indirectamente de la mortalidad materna (MSPBS, 2005).

El porcentaje de partos institucionales, que está asociado de manera positiva con la disminución de la mortalidad materna, es casi universal en Argentina (99,7\%) mientras que en Paraguay se deben realizar mayores esfuerzos para captar la totalidad de los partos (97\%), según datos de 2015 (MS, 2017; MSPBS, 2016). Además de garantizar la atención de calidad a las mujeres que llegan al servicio.

Otro aspecto que da cuenta de las disparidades entre países, en el ámbito de la salud materna, lo constituye el porcentaje de madres con la

20 El riesgo individual de morir a causa de embarazarse o parir aumentará según la cantidad de veces que una mujer se embarace. Cada vez que una mujer se embaraza, vuelve a correr el riesgo de la mortalidad materna, y los riesgos se acumulan durante su vida (Burgos, 2015). cantidad de controles prenatales mínimos requeridos en caso de bajo riesgo en cada país. Argentina presenta un buen cumplimiento (93,2\% de las madres tuvo 5 o más controles en 2013), en cambio, en Paraguay, la cifra desciende a $83,3 \%$ ( 4 o más controles) (MS, 2017; MSPBS, 2016). La importancia de las consultas prenatales viene dada por la promoción del conocimiento sobre la identificación y detección oportuna de factores de riesgo, señales de alarma o emergencias obstétricas que sirven para evitar muertes maternas (Mancuello, 2015).

Teniendo en cuenta que la falta de educación o escolaridad insuficiente crea barreras que impiden el acceso a la información y los servicios de salud, reduciendo las probabilidades de que las mujeres y sus familias utilicen y apoyen los servicios de salud ${ }^{21}$ (Arteaga y López, 2009), se observa que el porcentaje de población alfabetizada en Argentina supera al de Paraguay ( $98,1 \%$ y $95,9 \%$, respectivamente). En ambos países se reduce en las zonas rurales y en la población indígena, donde el español no es la lengua materna de las mujeres (Arteaga y López, 2009).

La Tabla Al del anexo muestra los indicadores del contexto sociodemográfico de la población en Argentina y Paraguay.

\section{Evolución, nivel y desigualdades de la mortalidad materna en Argentina y Paraguay}

En el contexto que se viene presentando es importante resaltar que, mientras la tasa de mortalidad infantil y la tasa global de fecundidad han disminuido en los últimos años en ambos países y la expectativa de vida al nacer se ha incrementado, la mortalidad materna no ha mostrado una reducción constante. La evolución de la razón de mortalidad materna a lo largo de las últimas dos décadas muestra una reducción más estable en Argentina, mientras en Paraguay

21 Además las mujeres analfabetas a menudo no conocen sus derechos humanos y legales básicos y las opciones que les ofrecen (Arteaga y López, 2009).

sociedad y economía • e-ISSN: 2389-9050 • No. 38, 2019 • pp. 21-44 
Figura 1. Razón de Mortalidad Materna registrada (por 100 mil nacidos vivos) según años, Argentina y Paraguay, promedios móviles trianuales, periodo 1990-2015

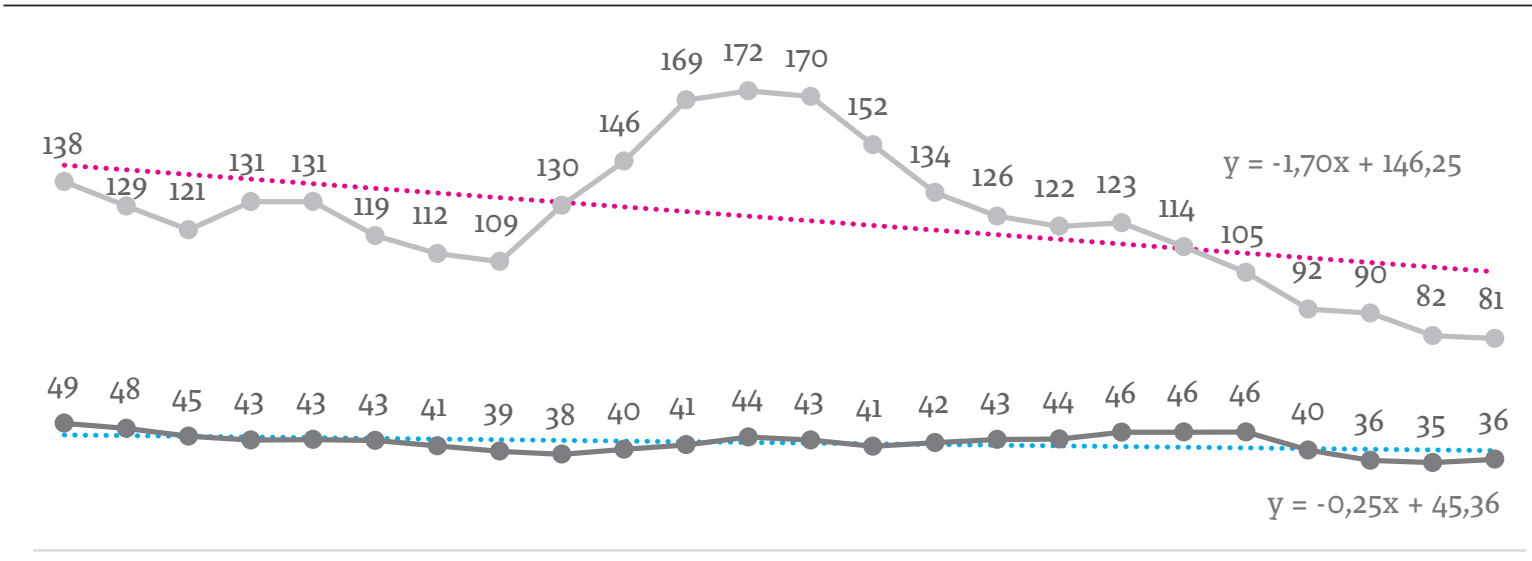

199119921993199419951996199719981999200020012002200320042005200620072008200920102011201220132014 $\longrightarrow$ Argentina $\quad . . . .$. Lineal (Argentina) $\quad$ Paraguay ........ Lineal (Paraguay)

Fuente: elaboración propia a partir de MS (1990-2015) y MSPBS (1990-2015).

las fluctuaciones son más marcadas ${ }^{22}$, con incrementos que pueden poner en peligro el cumplimiento de las metas de reducción asumidas en los compromisos internacionales.

Al analizar la evolución de la RMM trianual de Argentina y Paraguay, durante el periodo 19902015, se observa una gran diferencia entre ambos países. La RMM de Paraguay, en promedio, triplica a la de Argentina en el periodo analizado (Figura 1). En el último promedio trianual de la serie analizada, Argentina registró una RMM de 36 muertes maternas por cada 100 mil nacidos vivos, mientras en Paraguay dicho valor es 2,25 veces superior $(81$ muertes maternas por cada 100

22 Según Ruiz et al. (2015) estos altibajos pueden ser explicados por las inconsistencias en las bases de registros, tanto por mala clasificación como por problemas de cobertura. Para Brizuela (2005) es llamativo que en el año 2001 se rompa la tendencia, debido al descenso de las muertes por causas maternas en dicho año: la tasa materna bajó de 138 por 100 mil nacidos vivos, valor inferior al de los años contiguos y como aparentemente no existe ninguna razón para tal comportamiento, lo atribuye a la calidad de los registros. En 2013, el país vivió una coyuntura especial de salud debido a la epidemia de dengue que terminó con un saldo de 11 casos de muertes maternas (Ruiz et al., 2015). mil nacidos vivos). En 2009, Argentina presenta la mayor RMM del periodo analizado ( 55 muertes por cada 100 mil nacidos vivos), que es asociada a la Pandemia de Gripe A HiNı (MS, s.f.).

Teniendo en cuenta que en América Latina el promedio estimado de RMM, en 2015 , es de 60 muertes maternas por cada 100 mil nacidos vivos, Argentina se encuentra entre los países con mortalidad materna relativamente baja y Paraguay entre los de mortalidad intermedia (OPS, 2017).

La pendiente de la recta ajustada es descendente en ambos países con una reducción anual estimada de 1,7 defunciones por cada 100 mil nacimientos en Paraguay y 0,25 en Argentina (Figura 1). La diferencia absoluta muestra una reducción de 13 fallecimientos por cada 100 mil nacidos vivos en Argentina y de 68, en Paraguay, entre 1990 y 2015. Ninguno de estos dos países se encuentra entre los países de la región que más han avanzado en la reducción entre 1990 y 2013 (OMS, 2014).

El porcentaje de reducción de la razón de mortalidad materna, entre 1990 y 2015, es mayor en Paraguay frente al de Argentina (45,5\% y 25,6\%, respectivamente). Cabe señalar que Argentina tuvo una mortalidad materna tres veces más baja al inicio 
del periodo (52 en 1990), en comparación a Paraguay (150 en 1990) que experimenta actualmente un descenso más rápido. Si se separa el periodo analizado en dos tramos, se observa que en Argentina la reducción se mantiene prácticamente constante, siendo de $11,4 \%$ entre 1990 y 2002 , y de $11,2 \%$ entre 2003 y 2015. En tanto en Paraguay, la disminución es más significativa en el último periodo: $53 \%$ entre 2003 y 2015 (reducción anual promedio de $4 \%$ ), luego de haber presentado un incremento de $21,3 \%$ entre 1990 y 2002.

\subsection{Desigualdades territoriales}

El descenso de la RMM evidenciado a nivel nacional no se ha dado de manera equilibrada al interior de ambos países, revelando profundas desigualdades. En Argentina, la provincia de mayor RMM es cinco veces más elevada que la de menor RMM (Salta y Santa Cruz respectivamente), en tanto en Paraguay dicha brecha asciende a 6,8 veces y se da en departamentos de frontera (Boquerón y Misiones) (Anexo, Tabla A2.1 y Tabla A2.2).

Según Varela et al. (2014, citado en Binstock, 2016), el lugar de residencia implica un acceso a bienes y ser- vicios diversos, pero también a espacios de socialización y modelos y dinámicas sociales y culturales específicas. En este sentido, la mortalidad materna oculta la grave discriminación a la que están sujetas las poblaciones más vulnerables, es indicativa de condiciones socioeconómicas precarias, niveles de información general y de escolaridad bajos, y dificultades en el acceso a servicios de salud de calidad.

El análisis por departamentos (subdivisión político administrativa de Paraguay) y provincias (en Argentina) permite identificar cifras similares en los niveles de RMM a un lado y otro de la frontera de ambos países. Ello vuelve a comprobar la hipótesis de Fantin que plantea que "los que viven en la frontera argentino-paraguaya se parecen más a sí mismos que a los pares de sus respectivos países" (2008, p. vii) haciendo referencia a la media nacional.

Como se puede observar en la Tabla 1, el promedio de la RMM centrado en el año 2014 indica que las provincias que conforman el Nordeste argentino (Chaco, Formosa, Corrientes y Misiones) y que limitan con Paraguay, poseen niveles de mortalidad materna considerablemente superiores a la media del país. La situación más extrema la

Tabla 1. Razón de Mortalidad Materna registrada (por 100 mil nacidos vivos) en provincias (Argentina) y departamentos (Paraguay) fronterizos. Promedios trianuales, 2010-2015

\begin{tabular}{|c|c|c|c|c|}
\hline $\begin{array}{c}\text { Promedios móviles } \\
\text { trianuales }\end{array}$ & Centrado en 2011 & Centrado en 2012 & Centrado en 2013 & Centrado en 2014 \\
\hline \multicolumn{5}{|c|}{ Argentina } \\
\hline TOTAL & 39,5 & 35,8 & 34,9 & 36,2 \\
\hline Corrientes & 57,5 & 63,1 & 51,9 & 47,7 \\
\hline Chaco & 76,2 & 67,7 & 58,1 & 59,7 \\
\hline Formosa & 145,0 & 121,6 & 112,6 & 81,6 \\
\hline Misiones & 67,9 & 56,5 & 35,9 & 43,6 \\
\hline \multicolumn{5}{|c|}{ Paraguay } \\
\hline TOTAL & 91,5 & 90,0 & 81,7 & 80,7 \\
\hline Asunción & 85,3 & 77,3 & 59,5 & 49,1 \\
\hline Itapúa & 76,5 & 73,2 & 77,6 & 89,5 \\
\hline Misiones & 133,4 & 53,7 & 53,7 & 35,5 \\
\hline Alto Paraná & 103,5 & 106,4 & 105,4 & 104,8 \\
\hline Central & 65,2 & 82,0 & 80,4 & 71,5 \\
\hline Ñeembucú & 110,3 & 74,7 & 34,6 & 34,6 \\
\hline Pte. Hayes & 151,7 & 152,4 & 168,1 & 147,9 \\
\hline Boquerón & 73,9 & 98,3 & 74,8 & 166,3 \\
\hline
\end{tabular}


Figura 2. Distribución porcentual de muertes maternas registradas por grupos de edad, Argentina y Paraguay. Promedio trianual centrado en 2014

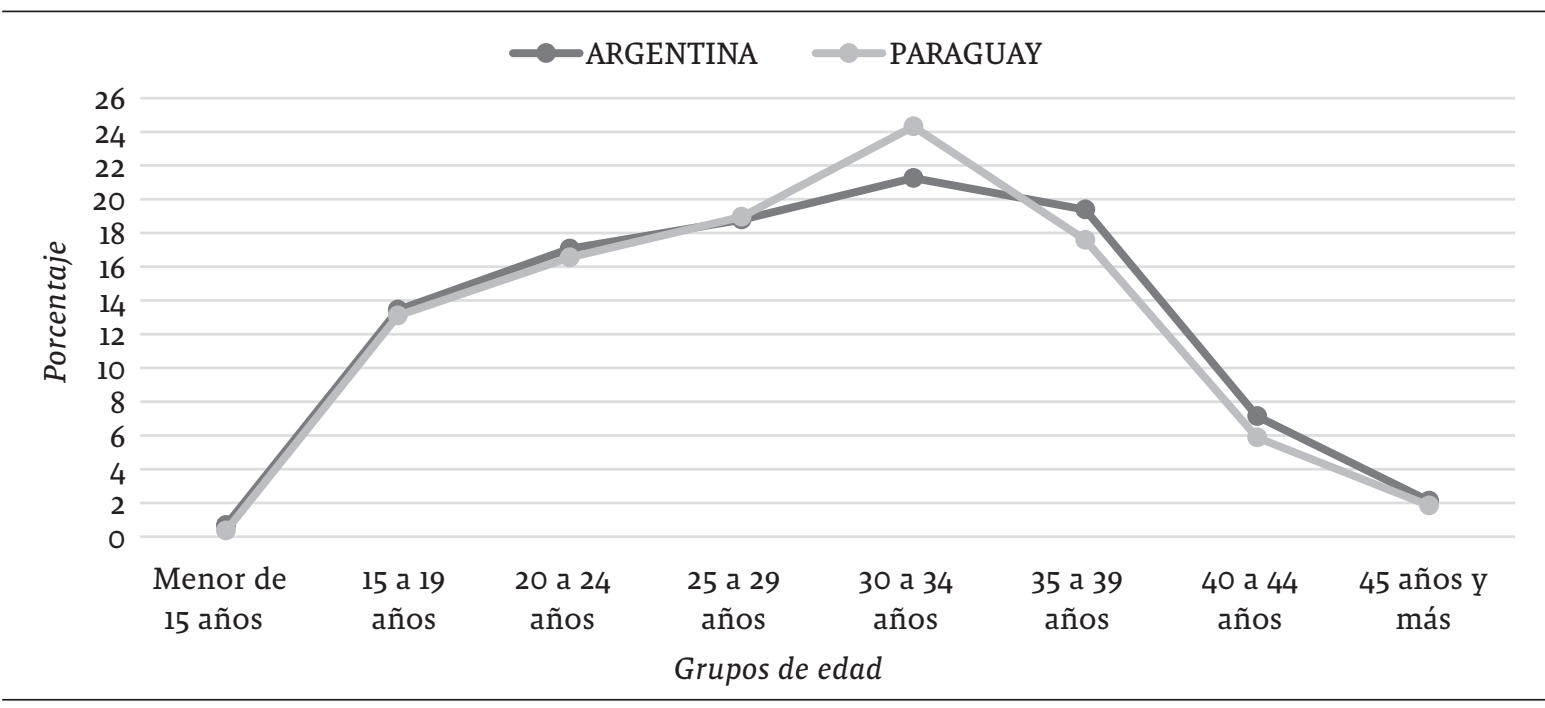

Fuente: elaboración propia a partir de MS (2010-2015) y MSPBS (2010-2015).

presenta la provincia de Formosa con una RMM de 81,6 defunciones maternas por cada 100 mil nacidos vivos, muy similar a las cifras encontradas en los departamentos de Paraguay que comparten la frontera con Argentina (promedio de 93,9 defunciones del lado paraguayo) (Anexo, Tabla A2.1 y Tabla A2.2).

Una parte importante de las defunciones maternas se distribuye en la zona de frontera, en especial en Paraguay. En 2015, las muertes maternas ocurridas en departamentos de Paraguay, en frontera con Argentina, representan el 40\% del total de defunciones maternas, en tanto, del lado argentino, las defunciones en provincias de frontera constituyen el $17,4 \%$ de todas las muertes del país. Esto es así puesto que en Argentina el $37,2 \%$ del total de muertes maternas se concentran en Buenos Aires, donde reside el $38,6 \%$ de la población.

La tendencia de la RMM no es homogénea en todas las provincias o departamentos que conforman la zona de frontera. Los promedios trianuales, del 2010 al 2015, muestran que del lado argentino la RMM aumentó en Chaco y Misiones, y en todo el periodo las provincias que conforman la frontera con Paraguay tienen va- lores por encima del promedio nacional. Por su parte, del lado paraguayo, el aumento se dio en dos de los siete departamentos (Itapúa y Boquerón) y la capital, que conforman la zona de frontera. En tanto, cinco departamentos superan la media nacional.

\section{Desigualdades por grupos de edad}

Las muertes maternas ocurren a lo largo del periodo de edad reproductiva de las mujeres, pero con mayor incidencia en el grupo de $30 \mathrm{a}$ 34 años, tanto en Argentina como en Paraguay (Figura 2), debido a que en dichas edades se da el mayor número de nacimientos.

$\mathrm{Al}$ analizar la RMM por grupos etarios, el mayor riesgo ocurre en las edades extremas del periodo reproductivo (Tabla 2), siendo las niñas y las adolescentes (10 a 19 años de edad) un grupo particularmente vulnerable a morir por causas del embarazo, parto o puerperio.

Según diversos estudios, entre los riesgos que corren las mujeres y sus hijos cuando el parto ocurre en la adolescencia, se encuentran niveles más altos de morbilidad y un alto riesgo de perder la vida durante el embarazo o el parto. 
Tabla 2. Razón de Mortalidad Materna registrada (por cien mil nacidos vivos) en Argentina y Paraguay por grupos etarios (año 2015).

\begin{tabular}{|c|c|c|c|c|c|c|c|c|c|}
\hline & $\begin{array}{c}\text { Menor de } \\
15 \text { años }\end{array}$ & $\begin{array}{c}15 \text { a } 19 \\
\text { años }\end{array}$ & $\begin{array}{c}20 \text { a } 24 \\
\text { años }\end{array}$ & $\begin{array}{c}25 \text { a } 29 \\
\text { años }\end{array}$ & $\begin{array}{c}30 \text { a } 34 \\
\text { años }\end{array}$ & $\begin{array}{c}35 \text { a } 39 \\
\text { años }\end{array}$ & $\begin{array}{c}40 \text { a } 44 \\
\text { años }\end{array}$ & $\begin{array}{c}45 \text { años y } \\
\text { más }\end{array}$ & Total \\
\hline Argentina & 143,5 & 38,6 & 22,7 & 35,9 & 37,4 & 61,9 & 63,1 & 626,8 & 38,7 \\
\hline Paraguay & 148,8 & 70,5 & 63,8 & 54,2 & 82,2 & 167,4 & 159,5 & 1357,5 & 81,8 \\
\hline
\end{tabular}

Fuente: elaboración propia a partir de MS (2015b) y MSPBS (2015).

El mayor riesgo obstétrico deriva de la desproporción fetopélvica, del trabajo de parto prolongado y de los partos prematuros. Cuanto más joven la mujer queda embarazada, mayores son los riesgos sanitarios para ella misma y para su bebé (Pantelides y Cerrutti, 1992; Binstock, 2016; OPS, 1990 citado en Rajs et al., 1994).

En promedio, una de cada siete muertes maternas en Argentina y Paraguay ocurre en niñas y adolescentes. Este hecho, de alarmarte gravedad, involucra principalmente a adolescentes ( 15 a 19 años) que pierden la vida a causa de problemas relacionados con el embarazo, parto y puerperio $^{23}$ (Anexo, Tabla A3).

\section{Principales causas de mortalidad materna en Argentina y Paraguay}

Este apartado aborda las principales causas inmediatas de mortalidad materna, sin embargo, es importante señalar que, según la OMS, para contrarrestar esas muertes también hay que identificar y modificar los factores que las generan, entre los cuales, se destacan los socioculturales (Elu y Santos, 2004).

En ambos países, las principales causas de muerte materna (excluyendo las clasificadas como "otras complicaciones del embarazo, parto y puerperio") están conformadas por el aborto, los trastornos hipertensivos (toxemia) y las complicaciones del puerperio, que incluyen la sepsis y las hemorra-

23 Se debe contemplar que la tasa de fecundidad adolescente (15 a 19 años), en 2016, en Paraguay, es más elevada que en Argentina (72, según MSPBS/DGEEC/UNICEF, 2017 , y 65 nacimientos por cada mil mujeres, entre 15 a 19 años, según CEPAL, 2017). gias. Estas últimas son consideradas causas directas que se relacionan con una intervención tardía e insegura, falta de equipos y recursos, ausencia de normas de manejo o de supervisión de las mismas, y se caracterizan por ser evitables. Una adecuada atención prenatal y durante el parto puede evitar significativamente decesos por toxemia, hemorragia y sepsis (Brizuela, 2005).

En Paraguay, los decesos por toxemia, hemorragia y sepsis representan casi la mitad de las defunciones maternas, en el período 2013-2015. En tanto, en Argentina, cobran mayor importancia las muertes ocasionadas por otras complicaciones (Figura 3) (Anexo, Tabla A4). Según Rajs et al. (1994) los pesos relativos de las toxemias y de las hemorragias son más relevantes en los países de peor cobertura de la atención prenatal y profesional del parto, respectivamente. La infección por el VIH/sida es también un contribuyente y causa indirecta de defunción materna.

El aborto ha sido, a través de los años, una importante causa de muerte materna, siendo responsable de aproximadamente una de cada cinco defunciones maternas. La interpretación de las cifras de mortalidad materna por dicha causa debe ser cautelosa: es probable que su peso sea mayor, en la realidad, debido al subregistro y el ocultamiento de que es objeto, ya que la interrupción voluntaria del embarazo es ilegal y por ende penada por ley en los países estudiados, salvo algunas causales en las que no es punible: en Argentina, en casos de violación y cuando representa un riesgo para la vida o la salud de la mujer (art. 86 del Código Penal, Ley No 11.179/1984, Congreso de la Nación Argentina, 1984); en Paraguay, en caso de peligro para la vida de la mujer (art. 109 del Código Penal, Ley No ${ }^{\circ} .160 / 1997$, Congreso de la Nación Paraguaya, 1997). 
Figura 3. Distribución porcentual de las principales causas de muertes maternas registradas, Argentina y Paraguay. Promedio trianual centrado en 2014

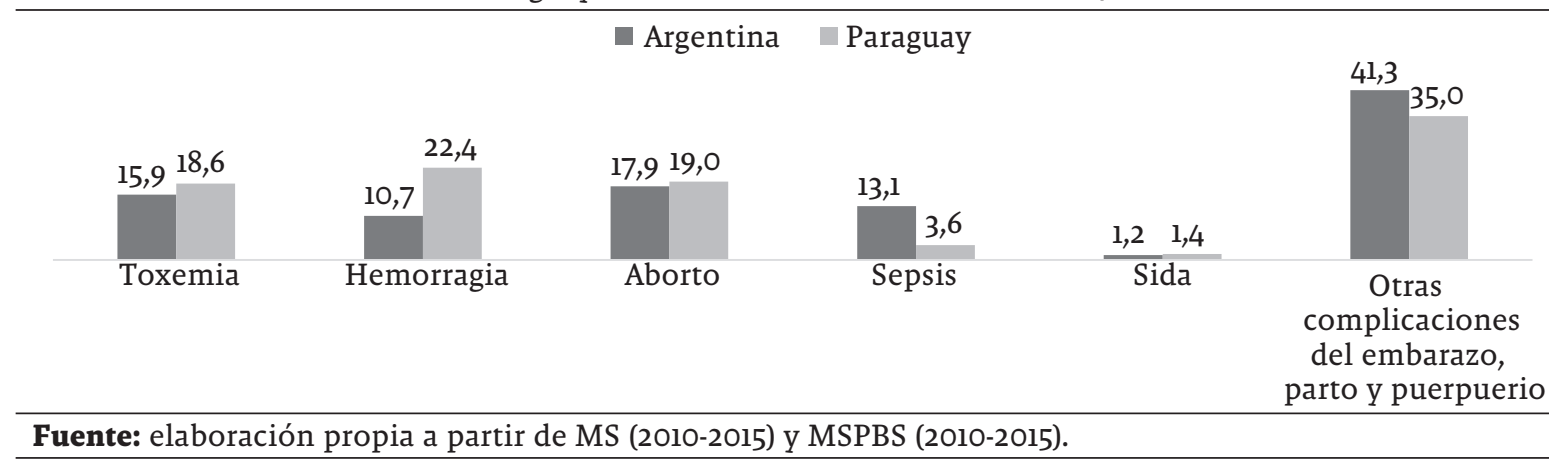

\section{Conclusiones}

Argentina y Paraguay comparten aspectos generales del sistema de salud pública, como la atención gratuita a toda persona que lo necesite, los marcos normativos que garantizan el ejercicio de los derechos sexuales y reproductivos de la población, los programas de salud sexual y reproductiva, y suministro de alimentación y nutrición adecuada para las mujeres embarazadas, a cargo de los Ministerios de Salud, además de ser signatarios de compromisos internacionales.

Sin embargo, la mortalidad materna presenta en esos países trayectorias diferentes. La muerte de una mujer por causas relacionadas al embarazo, parto o puerperio es un problema grave en $\mathrm{Pa}$ raguay, cuya magnitud, en 2015, duplica los valores registrados en Argentina, a pesar de los esfuerzos realizados en la última década mediante un mayor despliegue legal y programático para mejorar la salud materna.

Si bien Paraguay viene reduciendo, con altibajos, el número de mujeres que fallecen por causas relacionadas con el embarazo, se trata de un progreso importante, aunque no suficiente. Esto pone de manifiesto que el país debe implementar acciones prioritarias para mejorar el acceso y la calidad de los servicios de salud, y hacer frente a otros obstáculos que impiden una reducción significativa de la mortalidad materna.

Dichos obstáculos se relacionan con la falta de información o conocimiento, de medios para llegar hasta los servicios del nivel sanitario correspondiente, falta o escases de medicamentos e insumos, recursos humanos, infraestructura, tradiciones culturales, entre otros factores que se exacerban en contextos de pobreza, inequidad y marginalidad. La actual Política Nacional de Salud (2015-2030) plantea estrategias para lograr el acceso y la cobertura universal de salud en todo el territorio nacional, sin embargo, no hace mención explícita a la salud materna.

La zona de frontera de ambos países presenta un escenario particular, en el cual los niveles de mortalidad se alejan de los promedios nacionales y adquieren valores similares como producto de la interacción social, económica y cultural, evidenciando una inequitativa distribución de las muertes maternas sobre la superficie. Dicha zona debería ser objeto de políticas focalizadas orientadas a la salud materna-infantil y reproductiva que persigan la reducción de las brechas de disparidad interna de los países, en particular, en zonas aisladas debido a las marcadas diferencias de desarrollo económico entre las diversas regiones. En este sentido, el informe de gestión del "Plan Operativo para la Reducción de la Mortalidad Materna-infantil, de las madres y de las adolescentes" de Argentina, en el periodo $2009-2015^{24}$, da cuenta de la reduc-

24 El Plan Operativo ha sido concebido sin un horizonte de finalización predefinido. No obstante, en pos de facilitar la evaluación, las metas fueron inicialmente definidas para el año 2011, pero se extendieron y complementaron luego con metas definidas a diciembre de 2015 (MS, s.f.). 
ción de la mortalidad materna y la disminución en la brecha del riesgo de morir entre las jurisdicciones. No obstante, señala la necesidad de extender las acciones del Plan a los otros subsistemas de salud.

El análisis de las causas de mortalidad materna indica que los esfuerzos dirigidos a disminuir esta problemática deben estar orientados a las causas directas como toxemia y hemorragia, además del aborto. Al ser la mortalidad materna en gran medida evitable, se ubica como un problema de salud pública que exige una firme voluntad política para modificar las estructuras sociales y culturales, así como combatir la pobreza y la discriminación de género.

Lo expuesto demanda que dicha voluntad se refleje en la asignación de los recursos suficientes, en un abordaje intersectorial que, desde una perspectiva de derechos, ahonde en temas de educación sexual, en la prevención de los embarazos no deseados, el aumento del intervalo intergenésico, la prevención de los embarazos en edades de alto riesgo -en especial de adolescentes-, en los abortos y la atención pos aborto.

Para lograr reducir la mortalidad materna es necesario que las acciones de fortalecimiento de los sistemas de salud sean acompañadas de mejoras en otras áreas. La educación, por ejemplo, permite adquirir los conocimientos necesarios para rechazar prácticas tradicionales que aca- rrean riesgos para las mujeres y sus hijos (Arteaga y López, 2009). Todo lo mencionado pone de manifiesto los retos para la protección social, puesto que el acceso a los servicios de salud es un derecho, y el Estado debe ser garante de su otorgamiento, sobre todo a aquellas personas que no cuentan con seguridad social y para quienes el acceso a servicios de salud puede significar altos costos.

La salud materna y la reducción de la mortalidad materna deben seguir estando entre las prioridades de la agenda pública de los países analizados, con interacción y sinergias entre las personas, las comunidades, los centros de investigación, las agencias de cooperación, los organismos del Estado y los actores del sistema de salud para potenciar los resultados de los programas sanitarios.

Es importante también avanzar en la disminución del subregistro en las estadísticas vitales, así como reforzar los sistemas de información y vigilancia epidemiológica de las muertes maternas, a fin de disponer de datos actualizados y confiables que incluyan información sobre la manera, el lugar, el momento y la razón de las muertes. De modo que los programas de salud puedan asignar los recursos necesarios en intervenciones basadas en la evidencia, establecer prioridades más focalizadas, y permitir el seguimiento y la evaluación de los programas encaminados a reducir la mortalidad materna. 
Evolución de la mortalidad materna en Argentina y Paraguay entre 1990 y 2015; políticas públicas, desigualdades y desafíos

\section{Anexos}

Tabla Al. Indicadores de contexto sociodemográfico de la población, Argentina y Paraguay

\begin{tabular}{|c|c|c|c|c|}
\hline \multirow{2}{*}{ Indicador } & \multicolumn{2}{|c|}{ Argentina } & \multicolumn{2}{|c|}{ Paraguay } \\
\hline & Cifra & $\begin{array}{c}\text { Año de } \\
\text { información }\end{array}$ & Cifra & $\begin{array}{c}\text { Año de } \\
\text { información }\end{array}$ \\
\hline Población total & 43.298 .264 & 2015 & 6.639 .157 & 2015 \\
\hline $\begin{array}{l}\text { Tasa de crecimiento media anual de la población (por mil } \\
\text { habitantes) }\end{array}$ & 8,9 & 2015-2020 & 14,3 & $2015-2020$ \\
\hline Porcentaje de población rural & 8,2 & 2015 & 33,6 & 2015 \\
\hline Índice de masculinidad & 96,6 & 2015 & 103,0 & 2015 \\
\hline Porcentaje de la población menor a 30 años de edad & 48,6 & 2015 & 59,4 & 2015 \\
\hline Porcentaje de la población de 60 y más años de edad & 15,2 & 2015 & 9,0 & 2015 \\
\hline $\begin{array}{l}\text { Porcentaje de mujeres en edad reproductiva (15-49 años) } \\
\text { sobre el total de mujeres }\end{array}$ & 48,7 & 2015 & 53,0 & 2015 \\
\hline $\begin{array}{l}\text { Porcentaje de mujeres de } 10 \text { a } 19 \text { años de edad sobre el total } \\
\text { de mujeres }\end{array}$ & 15,5 & 2015 & 20,1 & 2015 \\
\hline Tasa Global de Fecundidad & 2,2 & $2015-2020$ & 2,4 & $2015-2020$ \\
\hline $\begin{array}{l}\text { Tasa de fecundidad en mujeres adolescentes por cada mil } \\
\text { mujeres de } 15 \text { a } 19 \text { años }\end{array}$ & 68 & 2017 & 72,0 & 2016 \\
\hline Tasa bruta de natalidad (por mil habitantes) & 16,5 & $2015-2020$ & 20,0 & $2015-2020$ \\
\hline Tasa bruta de mortalidad (por mil habitantes) & 7,6 & $2015-2020$ & 5,7 & $2015-2020$ \\
\hline Tasa de Mortalidad Neonatal (por mil nacidos vivos) & 6,6 & 2015 & 9,7 & 2015 \\
\hline Tasa de Mortalidad Infantil (por mil nacidos vivos) & 9,7 & 2015 & 14,2 & 2015 \\
\hline $\begin{array}{l}\text { Tasa de Mortalidad menores de } 5 \text { años (por mil nacidos } \\
\text { vivos) }\end{array}$ & 10,8 & 2015 & 16,4 & 2015 \\
\hline Esperanza de vida al nacer ambos sexos (años) & 76,8 & $2015-2020$ & 73,7 & $2015-2020$ \\
\hline $\begin{array}{l}\text { Tasa de uso de anticonceptivos modernos, mujeres de } 15 \text { a } \\
49 \text { años }\end{array}$ & 70 & 2017 & 67 & 2017 \\
\hline $\begin{array}{l}\text { Porcentaje de demanda satisfecha de anticonceptivos } \\
\text { modernos, mujeres de } 15 \text { a } 49 \text { años }\end{array}$ & 85 & 2017 & 81 & 2017 \\
\hline Porcentaje de madres con controles prenatales* & 93,2 & 2013 & 83,3 & 2015 \\
\hline Porcentaje de partos institucionales & 99,7 & 2015 & 97 & 2015 \\
\hline Porcentaje de parto por cesárea & 30,6 & 2013 & 48,7 & 2015 \\
\hline $\begin{array}{l}\text { Porcentaje de recién nacidos con un peso al nacer de } 2500 \\
\text { grs. como mínimo }\end{array}$ & 92,8 & 2015 & 94 & 2015 \\
\hline $\begin{array}{l}\text { Porcentaje de muertes maternas en mortalidad de mujeres } \\
\text { en edad fértil }\end{array}$ & 2,0 & 2015 & 6,4 & 2015 \\
\hline Porcentaje de alfabetismo en población de 10 años y más & 98,1 & 2010 & 95,9 & 2015 \\
\hline
\end{tabular}

Nota: *En el caso de Argentina corresponde a 5 o más controles y Paraguay 4 o más.

Fuente: elaboración propia a partir de CELADE (2017); MS (2013; 2015); MSPBS (2015); DGEEC (2015); MSPBS, DGEEC y UNICEF (2017) y UNFPA (2017). 
Tabla A2.1. Razón de Mortalidad Materna registrada (por 100 mil nacidos vivos) en provincias, Argentina, periodo $2010-2015$

\begin{tabular}{|c|c|c|c|c|c|c|}
\hline & 2010 & 2011 & 2012 & 2013 & 2014 & 2015 \\
\hline TOTAL & 43,8 & 39,8 & 34,9 & 32,5 & 37,3 & 38,7 \\
\hline Ciud. Aut. de Buenos Aires & 8,8 & 13,3 & 16,0 & 16,0 & 18,3 & 19,1 \\
\hline Buenos Aires & 44,3 & 31,6 & 30,5 & 29,7 & 34,0 & 38,6 \\
\hline Partidos del Aglom. GBA & 49,3 & 34,1 & 31,4 & 31,1 & 35,0 & 39,5 \\
\hline Catamarca & 14,7 & 76,0 & 31,6 & 15,2 & 43,9 & 0,0 \\
\hline Córdoba & 47,8 & 19,0 & 15,8 & 23,2 & 32,1 & 29,0 \\
\hline Corrientes & 58,6 & 52,8 & 61,1 & 75,4 & 19,1 & 48,4 \\
\hline Chaco & 74,8 & 85,8 & 68,1 & 49,3 & 57,0 & 73,2 \\
\hline Chubut & 30,1 & 50,9 & 51,6 & 39,7 & 30,4 & 40,6 \\
\hline Entre Ríos & 31,3 & 54,0 & 32,0 & 26,8 & 30,0 & 50,9 \\
\hline Formosa & 162,0 & 123,0 & 149,9 & 92,0 & 95,8 & 56,8 \\
\hline Jujuy & 37,3 & 115,4 & 77,5 & 7,6 & 21,4 & 75,4 \\
\hline La Pampa & 72,3 & 74,3 & 37,2 & 35,4 & 0,0 & 18,5 \\
\hline La Rioja & 114,4 & 63,4 & 15,9 & 111,9 & 159,1 & 31,9 \\
\hline Mendoza & 43,9 & 46,8 & 36,3 & 34,8 & 27,7 & 22,6 \\
\hline Misiones & 81,2 & 87,1 & 35,3 & 47,0 & 25,4 & 58,9 \\
\hline Neuquén & 32,8 & 26,7 & 18,0 & 17,8 & 16,8 & 33,8 \\
\hline Río Negro & 8,3 & 16,7 & 42,3 & 32,9 & 32,4 & 0,0 \\
\hline Salta & 57,6 & 39,4 & 45,3 & 51,3 & 81,1 & 81,0 \\
\hline San Juan & 42,3 & 41,7 & 20,8 & 53,7 & 58,0 & 59,3 \\
\hline San Luis & 37,8 & 38,6 & 26,2 & 0,0 & 25,2 & 37,0 \\
\hline Santa Cruz & 32,9 & 0,0 & 34,4 & 50,3 & 81,2 & 15,8 \\
\hline Santa Fe & 26,3 & 29,6 & 29,6 & 28,4 & 27,7 & 19,2 \\
\hline Santiago del Estero & 17,1 & 55,4 & 30,9 & 23,4 & 71,5 & 42,0 \\
\hline Tucumán & 29,6 & 36,8 & 44,8 & 17,0 & 39,5 & 36,4 \\
\hline Tierra del Fuego & 0,0 & 117,6 & 0,0 & 0,0 & 0,0 & 0,0 \\
\hline
\end{tabular}

Fuente: elaboración propia a partir de MS (2010-2015).

Tabla A2.2. Razón de Mortalidad Materna registrada (por 100 mil nacidos vivos) en departamentos, Paraguay,

\begin{tabular}{|c|c|c|c|c|c|c|}
\hline & 2010 & 2011 & 2012 & 2013 & 2014 & 2015 \\
\hline TOTAL & 100,8 & 88,8 & 84,9 & 96,3 & 63,9 & 81,8 \\
\hline Asunción & 88,1 & 84,4 & 83,4 & 64,1 & 31,0 & 52,1 \\
\hline Concepción & 122,3 & 116,4 & 93,4 & 71,8 & 90,8 & 153,1 \\
\hline San Pedro & 129,0 & 138,2 & 75,7 & 60,6 & 71,2 & 95,2 \\
\hline Cordillera & 100,3 & 72,0 & 93,4 & 24,1 & 22,4 & 65,9 \\
\hline Guairá & 105,4 & 136,2 & 67,0 & 100,9 & 33,0 & 99,3 \\
\hline Caaguazú & 101,7 & 104,0 & 49,4 & 90,3 & 72,4 & 93,8 \\
\hline Caazapá & 123,4 & 204,1 & 279,7 & 84,2 & 39,6 & 76,4 \\
\hline Itapúa & 80,0 & 95,0 & 54,5 & 70,1 & 108,3 & 90,2 \\
\hline Misiones & 294,3 & 0,0 & 105,9 & 55,1 & 0,0 & 51,4 \\
\hline Paraguarí & 64,1 & 32,2 & 63,6 & 66,1 & 63,6 & 62,8 \\
\hline Alto Paraná & 142,9 & 86,0 & 81,5 & 151,6 & 83,1 & 79,8 \\
\hline Central & 53,6 & 63,8 & 78,3 & 103,9 & 59,1 & 51,5 \\
\hline Ñeembucú & 107,1 & 224,0 & 0,0 & 0,0 & 103,7 & 0,0 \\
\hline Amambay & 162,6 & 73,5 & 65,7 & 35,6 & 66,6 & 190,4 \\
\hline Canindeyú & 209,6 & 96,4 & 156,3 & 158,8 & 29,7 & 167,1 \\
\hline Pte. Hayes & 155,8 & 148,2 & 151,2 & 157,8 & 195,2 & 90,5 \\
\hline Boquerón & 79,0 & 70,4 & 72,3 & 152,2 & 0,0 & 346,7 \\
\hline Alto Paraguay & 403,2 & 414,9 & 732,6 & 692,0 & 0,0 & 0,0 \\
\hline
\end{tabular}

Fuente: elaboración propia a partir de MSPBS (2010-2015). 
Evolución de la mortalidad materna en Argentina y Paraguay entre 1990 y 2015; políticas públicas, desigualdades y desafíos

Tabla A3. Número de muertes maternas registradas por grupos de edad y distribución porcentual de muertes maternas, Argentina y Paraguay, periodo 2010 a 2015

\begin{tabular}{|c|c|c|c|c|c|c|c|c|c|c|c|}
\hline Año & $10-14$ & $15-19$ & $20-24$ & $25-29$ & 30-34 & 35-39 & $40-44$ & $45-49$ & 50-54 & $\begin{array}{c}\text { No } \\
\text { especificado } \\
\end{array}$ & TOTAL \\
\hline \multicolumn{12}{|c|}{ Argentina } \\
\hline 2010 & 3 & 40 & 44 & 68 & 75 & 59 & 36 & 4 & 0 & 2 & 331 \\
\hline 2011 & 1 & 35 & 40 & 63 & 74 & 56 & 29 & 3 & 0 & 1 & 302 \\
\hline 2012 & 1 & 33 & 46 & 47 & 58 & 49 & 22 & 2 & 0 & 0 & 258 \\
\hline 2013 & 0 & 33 & 47 & 39 & 57 & 45 & 19 & 4 & 0 & 1 & 245 \\
\hline 2014 & 2 & 37 & 51 & 56 & 61 & 56 & 24 & 3 & 0 & 0 & 290 \\
\hline 2015 & 4 & 42 & 43 & 63 & 58 & 61 & 16 & 11 & 0 & 0 & 298 \\
\hline \multicolumn{12}{|c|}{ Paraguay } \\
\hline 2010 & 0 & 7 & 19 & 26 & 22 & 16 & 8 & 1 & 1 & 2 & 102 \\
\hline 2011 & 1 & 13 & 22 & 14 & 18 & 15 & 10 & 1 & 0 & 0 & 94 \\
\hline 2012 & 1 & 9 & 24 & 20 & 22 & 8 & 7 & 0 & 0 & 1 & 92 \\
\hline 2013 & 0 & ll & 18 & 18 & 27 & 18 & 7 & 1 & 0 & 3 & 103 \\
\hline 2014 & 0 & 10 & 8 & 17 & 20 & ll & 4 & 1 & 0 & 1 & 72 \\
\hline 2015 & 1 & 14 & 20 & 15 & 18 & 19 & 5 & 3 & 0 & 0 & 95 \\
\hline \multicolumn{12}{|c|}{ Promedio trianual centrado en 2014} \\
\hline Argentina & 2 & 37 & 47 & 53 & 59 & 54 & 20 & 6 & 0 & 0 & 278 \\
\hline Paraguay & 0 & 12 & 15 & 17 & 22 & 16 & 5 & 2 & 0 & 1 & 90 \\
\hline \multicolumn{12}{|c|}{ Distribución porcentual trianual centrado en 2014} \\
\hline Argentina & 0,7 & 13,4 & 17,1 & 18,8 & 21,3 & 19,4 & 7,1 & 2,1 & 0,0 & 0,1 & 100,0 \\
\hline Paraguay & 0,4 & 13,1 & 16,5 & 19,0 & 24,3 & 17,6 & 5,9 & 1,8 & 0,0 & 1,8 & 100,0 \\
\hline
\end{tabular}

Fuente: elaboración propia a partir MS (2010-2015) y MSPBS (2010-2015).

Tabla A4. Evolución de las principales causas de muerte maternas registradas, Razón de Mortalidad Materna y distribución relativa, Argentina y Paraguay, periodo 2010 a 2015

\begin{tabular}{|c|c|c|c|c|c|c|c|c|c|c|c|c|}
\hline \multirow{3}{*}{ Causas } & \multicolumn{6}{|c|}{ Argentina } & \multicolumn{6}{|c|}{ Paraguay } \\
\hline & 2010 & 2011 & 2012 & 2013 & 2014 & 2015 & 2010 & 2011 & 2012 & 2013 & 2014 & 2015 \\
\hline & \multicolumn{12}{|c|}{ Razón de Mortalidad Materna } \\
\hline Toxemia (O10-O16) & 4,9 & 5,4 & 6,4 & 5,2 & 7,2 & 4,8 & 16,8 & 18,0 & 16,6 & 18,7 & 15,1 & 10,3 \\
\hline Hemorragia (O20; O44-O46; O67; O72)* & 5,6 & 3,7 & 3,5 & 3,4 & 4,6 & 3,5 & 24,7 & 18,0 & 19,4 & 18,7 & 15,1 & 19,8 \\
\hline Aborto $(\mathrm{O} 00-\mathrm{O} 07)$ & 9,0 & 9,6 & 4,5 & 6,6 & 5,5 & 7,1 & 26,7 & 19,8 & 13,8 & 18,7 & 13,3 & 13,8 \\
\hline Sepsis $(075.3 ; 085)^{* *}$ & 4,8 & 4,1 & 5,0 & 4,1 & 5,1 & 4,9 & 6,9 & 1,9 & 1,8 & 0,0 & 3,6 & 4,3 \\
\hline Tétanos obstétrico $(\mathrm{A} 34)^{* * *}$ & 0,0 & 0,0 & 0,0 & 0,0 & 0,0 & 0,0 & 0,0 & 0,0 & 0,0 & 0,0 & 0,0 & 0,0 \\
\hline Sida (B2O-B24) & 0,3 & 0,1 & 0,5 & 0,3 & 0,8 & 0,3 & 2,0 & 0,0 & 0,9 & 2,8 & 0,9 & 0,0 \\
\hline $\begin{array}{l}\text { Otras complicaciones del embarazo, } \\
\text { parto y puerpuerio (O21-O29; O30-O43; } \\
\text { O47-O48;O60-O66; O68-O71; O73-O75; } \\
\text { O86-092; O95-O99) }\end{array}$ & 19,3 & 16,9 & 15,0 & 12,9 & 14,0 & 18,1 & 23,7 & 31,2 & 32,3 & 37,4 & 16,0 & 33,6 \\
\hline Total & 43,8 & 39,8 & 34,9 & 32,5 & 37,3 & 38,7 & 100,8 & 88,8 & 84,9 & 96,3 & 63,9 & 81,8 \\
\hline
\end{tabular}

Notas: * En el caso de Argentina no se reporta la categoría O20 y O67 incluidas dentro de otras causas directas.

** En el caso de Argentina no se reporta la categoría 075.3 y sin embargo incluye la 092 que en el caso de Paraguay está incluido en otras complicaciones

*** No reportado en el caso de Argentina

**** En el caso de Argentina se han agrupado las categoría Muerte obstétrica de causa no especificada (095), Otras causas directas (O20-029; 030-043; O47-048; O60-069; 070-071; 073-075; O95), Enf. del Sist. Circulatorio que complican el embarazo, el parto y el puerperio (0994), Enf. del Sist. Respiratorio que complican el embarazo, el parto y el puerperio (O995), Enf. del Sist. Digestivo que complican el embarazo, el parto y el puerperio (0995) y Otras causas indirectas.

Fuente: elaboración propia a partir de MS (2010-2015) y MSPBS (2010-2015). 
Tabla A4. Evolución de las principales causas de muerte maternas registradas, Razón de Mortalidad Materna y distribución relativa, Argentina y Paraguay, periodo 2010 a 2015 (continuación)

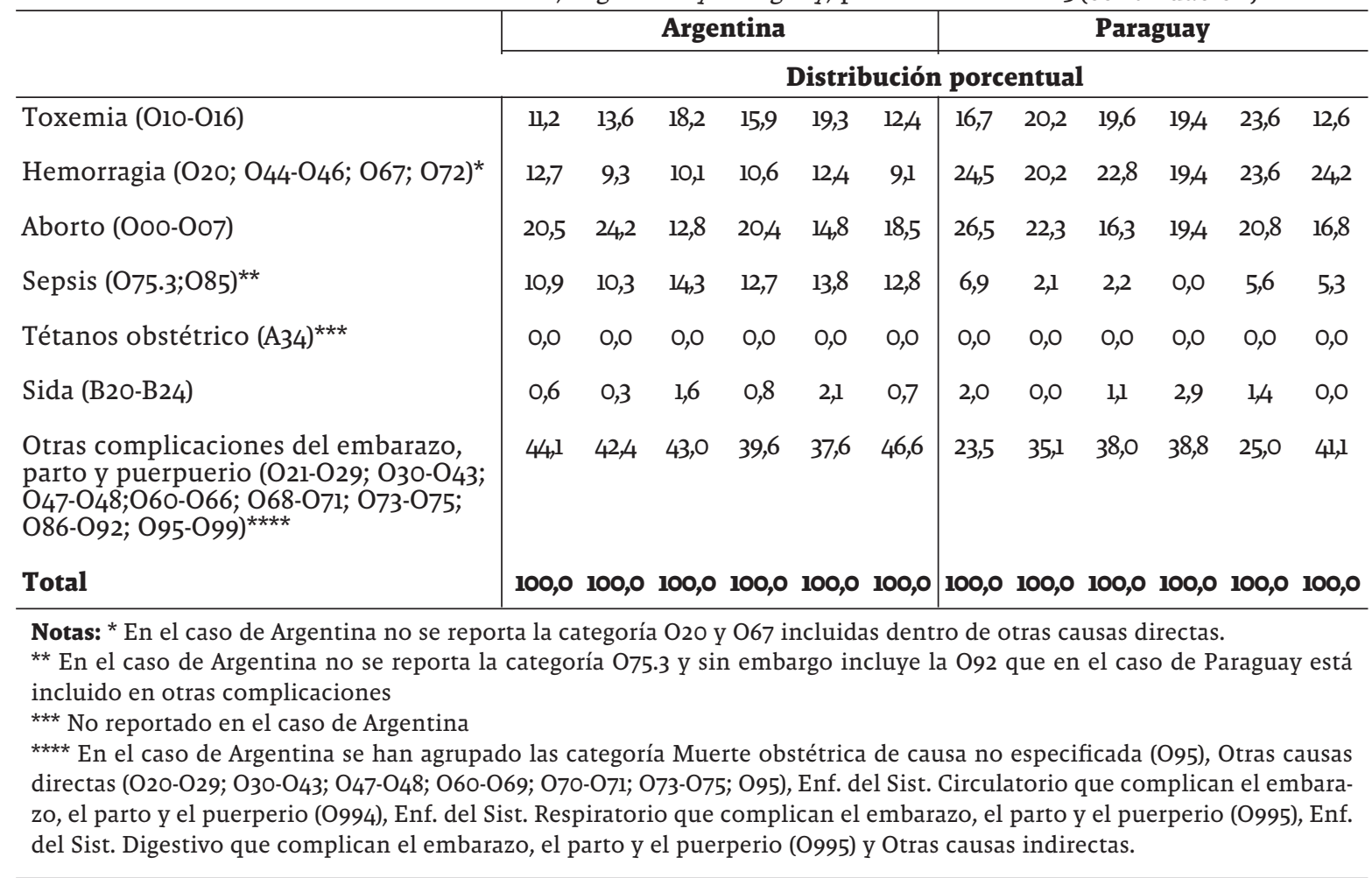

Fuente: elaboración propia a partir de MS (2010-2015) y MSPBS (2010-2015).

\section{Referencias bibliográficas}

Acosta G. (1999). Vía crucis de la muerte materna - documento de trabajo. Washington, US: UNICEF, Oficina Regional para América Latina y el Caribe.

Arteaga, F. A. M. y López, S. N. (2009). Evolución de la mortalidad materna en América Latina, El Caribe y Bolivia. Aspectos que influyen. Arch.Boliv.Med., 13(81), 35-40.

Binstock, G. (2016). Fecundidad y maternidad adolescente en el Cono Sur: apuntes para la construcción de una agenda común. Ciudad de Panamá, Panamá: UNFPA.

BM -Banco Mundial-. (2006). Mortalidad Materna: datos básicos. Recuperado de http://siteresources.worldbank. org/INTPHAAG/Resources/AAGMaternalMortalitySp.pdf

Brizuela, F. (2005). Mortalidad: evolución y tendencias: 1970-2000. Fernando de la Mora, Paraguay: DGEEC Publicaciones.

Burgos B., A. (2015). Políticas públicas en América Latina para la reducción de la mortalidad materna, $2009-2014$. Serie Población y Desarrollo $n^{\circ}$ 112. Santiago, Chile: CEPAL. Recuperado de https://repositorio.cepal.org/ bitstream/handle/11362/39303/1/S1500990_es.pdf

CELADE -Centro Latinoamericano y Caribeño de Demografía-. (2005). Dinámica demográfica y desarrollo en América Latina y el Caribe. Santiago, Chile: CEPAL, Serie Población y Desarrollo, № 58. 
Evolución de la mortalidad materna en Argentina y Paraguay entre 1990 y 2015; políticas públicas, desigualdades y desafíos

CELADE -Centro Latinoamericano y Caribeño de Demografía-. (2017). Estimaciones y proyecciones de población a largo plazo. 1950-2100. Revisión 2017. Recuperado de https://www.cepal.org/celade/proyecciones/ basedatos_BD.htm

CELADE -Centro Latinoamericano y Caribeño de Demografía- y CEPAL -Comisión Económica para América Latina y el Caribe-. (2017). Estimaciones y proyecciones de población a largo plazo. 1950-2100. Revisión 2017. Santiago, Chile: CEPAL.

CEPAL-Comisión Económica para América Latina y el Caribe-.(2017).Base de Datos Mundial. Recuperado de http:// interwp.cepal.org/sisgen/ConsultaIntegrada.asp?IdAplicacion=1\&idTema=1\&idIndicador=1702\&idioma=e

CEPEP -Centro Paraguayo de Estudios de Población-. (2009). Encuesta Nacional de Demografía y Salud Sexual y Reproductiva, ENDSSR 2008: informe final. Asunción, Paraguay: CEPEP.

Congreso de la Nación Argentina. (1984). Ley $N^{\circ}$ 11.179. Código Penal de la Nación Argentina. Recuperado de http://servicios.infoleg.gob.ar/infolegInternet/anexos/15000-19999/16546/texact.htm\#1

Congreso de la Nación Argentina. (2002a). Ley $N^{o}$ 25.584. Prohíbese en los establecimientos de educación pública toda acción institucional que impida el inicio o continuidad del ciclo escolar a alumnas embarazadas. Recuperado de http://servicios.infoleg.gob.ar/infolegInternet/anexos/70000-74999/74073/norma.htm

Congreso de la Nación Argentina. (2002b). Ley Nacional $N^{o}$ 25.673. De creación del Programa Nacional de Salud Sexual y Procreación Responsable. Recuperado de http://www.msal.gob.ar/images/stories/ministerio/ adolescencia/ley-25673.pdf

Congreso de la Nación Argentina. (2006). Ley $N^{\circ}$ 26.150. Programa Nacional de Educación Sexual Integral. Recuperado de http://www.sipi.siteal.iipe.unesco.org/sites/default/files/sipi_normativa/argentina_ley_ nro_26150_2006.pdf

Congreso de la Nación Paraguaya. (1992). Ley $N^{\circ}$ 1/92 de Reforma parcial del Código Civil. Recuperado de https:// www.pj.gov.py/images/contenido/secretariadegenero/marcolegal/LEY-1-1992.pdf

Congreso de la Nación Paraguaya. (1993). Ley $N^{0}$ 213/93 que establece el Código del Trabajo. Recuperado de http://www.mtess.gov.py/application/files/9914/3628/9949/ley213-93codigolaboral.pdf

Congreso de la Nación Paraguaya. (1997). Ley $N^{0}$ 1.160/1997 Código Penal de Paraguay. Recuperado de https:// www.oas.org/dil/esp/codigo_penal_paraguay.pdf

Congreso de la Nación Paraguaya. (1998). Ley No 1264/1998 General de Educación. Recuperado de http://www.pol. una.py/sites/default/files/files/reglamentos/Leyl264GeneralDeEducacion.pdf

Congreso de la Nación Paraguaya. (2001). Ley $N^{0}$ 1.680/2001 Código de la Niñez y la Adolescencia. Recuperado de https:/www.ilo.org/dyn/natlex/docs/ELECTRONIC/59808/101441/F1424950508/PRY59808.pdf

Congreso de la Nación Paraguaya. (2006). Ley $N^{\circ}$ 2907. Aseguramiento presupuestario de los programas de salud reproductiva y de aprovisionamiento del kit de partos del Ministerio de Salud Pública y Bienestar Social. Recuperado de http://www.bacn.gov.py/leyes-paraguayas/1990/aseguramiento-presupuestario-de-losprogramas-de-salud-reproductiva-y-de-aprovisionamiento-del-kit-de-partos-del-ministerio-de-salud-publicay-bienestar-social

Congreso de la Nación Paraguaya. (2010). Ley $N^{\circ}$ 4.084/2010. De protección a las estudiantes en estado de gravidez $y$ maternidad. Recuperado de https://abogado-oscar-galeano.blogspot.com/2016/07/ley-4084-2010-deproteccion-las.html

Congreso de la Nación Paraguaya. (2015). Ley $N^{\circ}$ 5.508/2015. De protección de la maternidad y apoyo a la lactancia. Recuperado de http://www.hacienda.gov.py/normativa/Ley\%205508-2015\%20De\%20proteccion\%20de\%20 la\%20maternidad\%20y\%20apoyo\%20a\%20la\%20lactancia\%20materna.pdf 
DGEEC -Dirección General de Estadística, Encuestas y Censos-. (2015). Encuesta Permanente de Hogares 2015. Paraguay Recuperado de http://www.dgeec.gov.py/microdatos_EPH/

Elu, M. C. y Santos, P. E. (2004). Mortalidad materna: una tragedia evitable. Perinatología y reproducción humana, 18(1), 44-52.

Fantin, M. A. (2008). Población, sociedad y salud en la frontera argentino-paraguaya. Asunción, Paraguay: IIGHI, UNFPA, ADEPO.

Gómez, G. E. (1997). La salud y las mujeres en América Latina y el Caribe. Viejos problemas y nuevos enfoques. Serie Mujer y Desarrollo N $^{\circ}$ 17. Santiago, Chile: CEPAL.

GTR -Grupo de Trabajo Regional para la Reducción de la Mortalidad Materna-. (2012). Estimaciones de Mortalidad Materna en América Latina y el Caribe: Un breve panorama. Recuperado de http://www.familycareintl.org/ UserFiles/File/GTR_SP.pdf

Hill, K., Stanton, C. y Gupta, N. (2001). Medición de la Mortalidad Materna a partir de un Censo: Instrucciones para los Usuarios. MEASURE Evaluation Manual Series, No. 4. North Carolina, US: MEASURE Evaluation.

Karolinski, A., Mercer, R., Micone, P., Ocampo, C., Salgado, P. y Szulik, D. (2015). Modelo para abordar integralmente la mortalidad materna y la morbilidad materna grave. Rev Panam Salud Pública, 37(4/5), 351-359. http://flacso. org.ar/wp-content/uploads/2015/07/Modelo-para-abordar-integralmente-la-mortalidad-materna.pdf

Mancuello, J. N. (2015). Para una maternidad segura en Paraguay. Revista Salud Pública del Paraguay, 5(1), 26-32. Recuperado de http://revistas.ins.gov.py/index.php/rspp/article/view/319

MS -Ministerio de Salud de la Nación, Argentina-. (2009). Plan operativo para la reducción de la mortalidad materno infantil, de las madres $y$ de las adolescentes. Recuperado de http://www.msal.gob.ar/ plan-reduccion-mortalidad/

MS -Ministerio de Salud de la Nación, Argentina-. (2013). Encuesta Nacional de Salud Sexual y Reproductiva Argentina 2013. Recuperado de http://www.msal.gob.ar/images/stories/bes/graficos/0000000729cntENCUESTA_NACIONAL_sobre_salud_sexual_Y_reproductiva.pdf

MS -Ministerio de Salud de la Nación, Argentina-. (2015a). Estadísticas Vitales. Información Básica. Serie 5 № 59. Ciudad Autónoma de Buenos Aires, Argentina: MS.

MS -Ministerio de Salud de la Nación, Argentina-. (2015b). Boletín de Indicadores Básicos Argentina 2015. Recuperado de http://www.deis.msal.gov.ar/index.php/indicadores-basicos/

MS -Ministerio de Salud de la Nación, Argentina-. (1990-2015). Estadísticas vitales, Natalidad, mortalidad general, infantil y materna por lugar de residencia Año 1990-2015. Recuperado de http://www.deis.msal.gov.ar/index. php/estadisticas-vitales/

MS -Ministerio de Salud de la Nación, Argentina-. (2017). Indicadores Básicos Argentina 2017, OPS-OMS. Ciudad Autónoma de Buenos Aires, Argentina: MS.

MS -Ministerio de Salud de la Nación, Argentina-. (s.f.). Plan para la Reducción de la Mortalidad Materno Infantil, de la Mujer y Adolescentes. Informe de gestión 2009-2015. Analizando el camino recorrido, aportando al camino por recorrer. Recuperado de http://www.msal.gob.ar/images/stories/banners/gestion_sanitaria_2009-2015/ informe-gestion-2009-2015.pdf

MS -Ministerio de Salud de la Nación, Argentina- y UNICEF -Fondo de las Naciones Unidas para la Infancia-. (2003). Mortalidad Materna. Un problema de salud pública y derechos humanos. Buenos Aires, Argentina: UNICEF.

MSPBS -Ministerio de Salud Pública y Bienestar Social-. (2005). Diagnostico estratégico, factores que influyen en la mortalidad materna en Paraguay. Asunción, Paraguay: MSPBS. 
Evolución de la mortalidad materna en Argentina y Paraguay entre 1990 y 2015; políticas públicas, desigualdades y desafíos

MSPBS -Ministerio de Salud Pública y Bienestar Social-. (2012). Plan de acción para la reducción acelerada de la mortalidad materna y la morbilidad materna grave Paraguay. Asunción, Paraguay: MSPBS.

MSPBS -Ministerio de Salud Pública y Bienestar Social-. (2015). Boletín de Indicadores Básicos de Salud Paraguay 2015. Recuperado de http://portal.mspbs.gov.py/digies/publicaciones/indicadores/

MSPBS -Ministerio de Salud Pública y Bienestar Social-. (1990-2015). Indicadores de Mortalidad INDIMOR Año 1990-2015, Paraguay. Recuperado de http://portal.mspbs.gov.py/ digies/o6-serie-historicas-indicadores-mortalidad-indimor/

MSPBS -Ministerio de Salud Pública y Bienestar Social-. (2016). Indicadores Básicos de Salud Paraguay 2016, OPS-OMS. Asunción, Paraguay: MSPBS.

MSPBS/DGEEC/UNICEF -Ministerio de Salud Pública y Bienestar Social - Dirección General de Estadística, Encuestas y Censos - Fondo de las Naciones Unidas para la Infancia-. (2017). Encuesta de indicadores múltiples por conglomerados MICS Paraguay 2016, Resultados principales. Asunción, Paraguay: DGEEC.

MSPBS/DIGIES/DES -Ministerio de Salud Pública y Bienestar Social - Dirección de Estadísticas en Salud Dirección de Información Estratégica en Salud-. (2015). Indicadores de Mortalidad de Paraguay - INDIMOR, Año 2015. Asunción, Paraguay: MSPBS.

OMS -Organización Mundial de la Salud-. (1992). Clasificación Internacional de Enfermedades, X Revisión. Ginebra, Suiza: OMS.

OMS -Organización Mundial de la Salud-. (2014). Trends in Maternal Mortality: 1990 to 2013. Ginebra, Suiza: WHO, UNICEF, UNFPA, World Bank, United Nations Population Division.

OMS -Organización Mundial de la Salud-. (2015). Trends in Maternal Mortality: 1990 to 2015. Ginebra, Suiza: OMS.

OMS -Organización Mundial de la Salud-. (2018). Nota descriptiva de la OMS sobre mortalidad materna. Recuperado de http://www.who.int/es/news-room/fact-sheets/detail/maternal-mortality

OPS -Organización Panamericana de la Salud-. (1995). Clasificación Internacional de Enfermedades y Problemas relacionados con la Salud - Décima revisión. Washington, US: OPS.

OPS -Organización Panamericana de la Salud-. (2017). Salud en las Américas edición del 2017. Resumen: panorama regional y perfiles de país. Washington D.C., US: OPS.

Padilla, K. y McNaughton, H. (2003). La mortalidad materna en Nicaragua: una mirada rápida a los años 20002002. Managua, Nicaragua: Ipas Centro América.

Pantelides, E. y Cerrutti, M. S. (1992). Conducta reproductiva y embarazo en la adolescencia. Buenos Aires, Argentina: CENEP.

Rajs, D., Parada, S. y Peyser, A. (1994). La mortalidad materna en América Latina y el Caribe. Notas de población. Santiago de Chile, Chile: CEPAL. Recuperado de https://repositorio.cepal.org/bitstream/handle/11362/12499/ NP60-07_es.pdf? sequence=1

Rodríguez, D. y Verdú, J. (2003). Consecuencias de una muerte materna en la familia. Aquichan, 13(3), 433-441. Recuperado de http://aquichan.unisabana.edu.co/index.php/aquichan/article/view/2503/3344

Ruiz, M. T., Miller, T., Márquez, L. y Villarroel, M. C. (2015). Hacia la armonización de las estimaciones de mortalidad materna en América Latina. Actualización y ampliación a los 20 países de la región. Serie Población y Desarrollo $N^{\circ} 111$. Santiago, Chile: CEPAL.

UNFPA -Fondo de Población de las Naciones Unidas-. (2017). Estado de la población mundial 2017, Mundos Aparte, La salud y los derechos reproductivos en tiempos de desigualdad. New York, US: UNFPA. 
UNFPA -Fondo de Población de las Naciones Unidas-, UNICEF -Fondo de las Naciones Unidas para la Infanciay ONU Mujeres -Entidad de las Naciones Unidas para la igualdad de Género y el Empoderamiento de las Mujeres-. (2018). Salud y Mortalidad Materna de las Mujeres Indígenas, hoja informativa. Recuperado de http://lac.unfpa.org/sites/default/files/pub-pdf/factsheet_v2O_Spanish\%20\%281\%29.pdf

UNICEF -Fondo de las Naciones Unidas para la Infancia-. (2009). Estado Mundial de la Infancia 2009. New York, US: UNICEF.

Uribe, R. (2009). Mortalidad Materna. Recuperado de http://www.facmed.unam.mx/sms/temas/2009/o1_ ene_2k9.pdf 